\title{
Reducing the extent of facetectomy may decrease morbidity in failed back surgery syndrome
}

\author{
Jingchi $\mathrm{Li}^{1,2}$, Xiaoyu Zhang ${ }^{2}$, Wenqiang $\mathrm{Xu}^{1}$, Zhipeng $\mathrm{Xi}^{1}$ and Lin $\mathrm{Xie}^{1,2^{*}}$
}

\begin{abstract}
Background: Percutaneous transforaminal endoscopic discectomy (PTED) is widely used for the treatment of lumbar disc herniation. Facetectomy in PTED is necessary for accessing the intraspinal region and for decompressing the exiting nerve roots in patients who suffer from hypertrophy of the facet joints. However, this may increase morbidity in failed back surgery syndrome (FBSS) and has not been clearly elucidated.

Methods: A three-dimensional lumbosacral model was reconstructed and validated. And corresponding models after PTED with one-quarter and one-half excisions of the superior articular process were reconstructed. The maximum shear stress on the annulus in $L 5$, von Mises stress of the facet cartilage, maximum principle capsular strain and deformation of the lumbosacral model were calculated using finite element methods.

Results: Calculated results show no significant differences in the complete model and the model with one-quarter excision of the superior articular process, but all biomechanical indexes have been deteriorated under most of the loading conditions tested in the model with one-half excision of the superior articular process.
\end{abstract}

Conclusions: Less facetectomy is better because it may reduce the risk of biomechanical deterioration and consequently, that of FBSS.

Keywords: Percutaneous transforaminal endoscopic discectomy, Facetectomy, Failed back surgery syndrome, Finite element research

\section{Background}

Failed back surgery syndrome (FBSS) is a frequently occurring postoperative complication [1]. Many studies have reported that biomechanical deterioration is the most crucial reason for postoperative complications such as FBSS [2-6].

Percutaneous transforaminal endoscopic discectomy (PTED) has already been used in the treatment of lumbar disc herniation (LDH) [7, 8]. In PTED, it is necessary to perform facetectomy to expand the neuroforamen. And in patients who suffer from hypertrophy of the facet joints, extensive facetectomy is needed for the decompression of exiting nerve roots. However, such a

\footnotetext{
*Correspondence: xielin6508@163.com

'Department of Orthopedic Surgery, Jiangsu Province Hospital on Integration of Chinese and Western Medicine, 100th .Shizi Street, Nanjing, 210028 Jiangsu Province, People's Republic of China

${ }^{2}$ Department of Spine Surgery, Third Clinical Medical College of Nanjing

University of Chinese Medicine, Nanjing 210028, Jiangsu, China
}

procedure may be closely associated with postoperative complications (Fig.1).

Aetiologies related to facet joints involved in the pathogenesis of low back pain (LBP) occur in $15-37 \%$ of patients after surgery $[9,10]$, and injury to the facet joint has been reported to cause a series of postoperative complications $[6,11]$. Meanwhile, tears in the posterior annulus is an important trigger for discogenic LBP and $\mathrm{LDH}$, which are two principal causes of FBSS $[1,12,13]$. The facet cartilage plays a key role in protecting the posterior annulus during torsion, and the capsule of the facet joint plays a similar role during flexion [14, 15]. Given that facetectomy does not directly cause injury to the articular surface and the capsule, variation in the stress distribution may result in secondary damage and increase the incidence of annulus tears [1, 12]. Furthermore, rich innervation is a typical histological feature of the facet capsule, and any increase in the mobility of the 


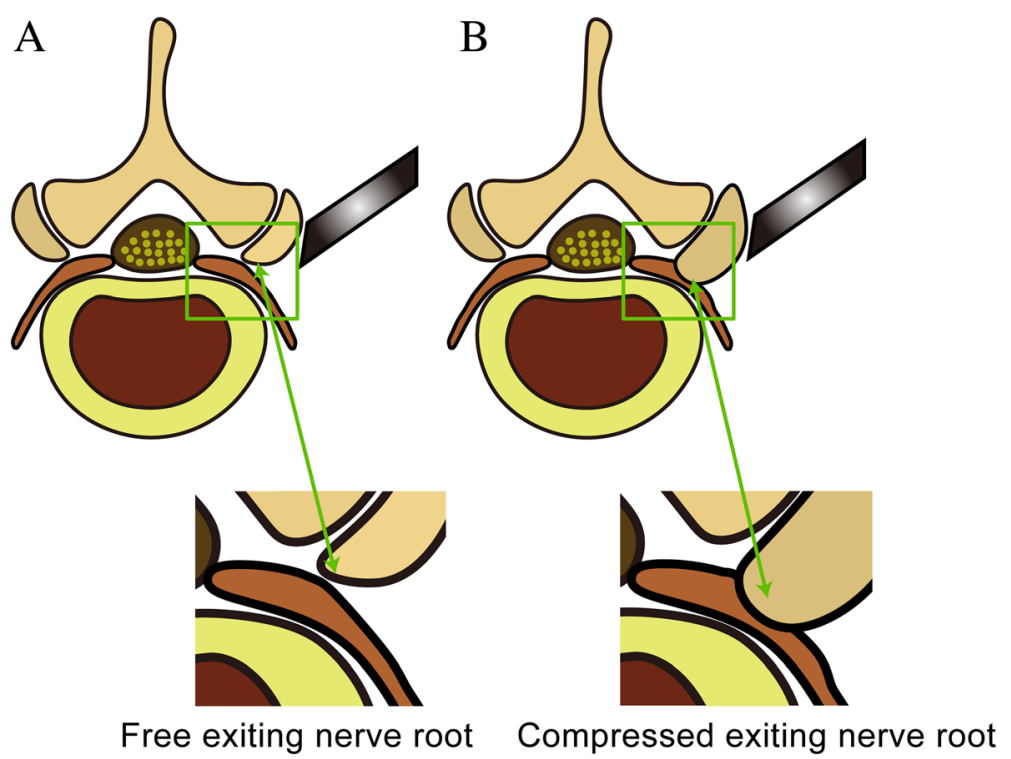

Fig. 1 The necessity of facetectomy in patients suffer from exiting nerve roots compression. a. Free exiting nerve root. $\mathbf{b}$. Compressed exiting nerve root

facet joint will affect the strain on the capsule and stimulate the nociceptors, thereby leading to LBP [16, $17,18]$. In addition, surgical intervention will change the force applied on the facet cartilage, leading to possible degeneration $[19,20]$. Besides, the facet joint is important in the maintenance of spine stability $[16,21]$, and iatrogenic instability is common in patients suffering from FBSS $[22,23]$. Taken together, we hypothesise that facetectomy and extensive facetectomy increase the risk of FBSS. However, this conjecture lacks the theoretical basis of biomechanics.

As a mechanical simulation research method, finite element analysis has been widely used in the investigation of postoperative biomechanical variations to infer the risk of postoperative complications [3-5, 24]. To clarify our hypothesis and provide theoretical guidance for the PTED application, we reconstructed a lumbosacral finite element model (FEM) to determine whether varying extents of facetectomy will affect its biomechanical indexes. To the best of our knowledge, published literatures have not adequately clarified this issue.

\section{Method}

\section{L3-S1 FEM of a healthy spine}

A three-dimensional model from L3 to S1 was reconstructed based on high-resolution computed tomography (CT) image of a 24-year-old male volunteer who was one of the authors of this manscript and without any history of lumbar diseases. The model comprised four vertebral bodies, three segments of intervertebral discs (IVDs), six facet joints and six ligaments. Components that could not be clearly distinguished by $\mathrm{CT}$ were reconstructed based on anatomical observations [4, 24].

The bone structure included a cortical bone shell $(0.8 \mathrm{~mm})$, a cancellous bone core, two endplates $(0.8$ $\mathrm{mm}$ ) and posterior structure. The IVD consisted of the inner nucleus and the surrounding annulus, and the nucleus occupied $44 \%$ of the cross-sectional area of the IVD and was located slightly posterior to the centre of the disc $[25,26]$. Facet joints consisted of the surrounding capsule and two cartilage surfaces $(0.25 \mathrm{~mm})[4,5]$. Ligaments, which include the anterior longitudinal ligament, posterior longitudinal ligament, ligamentum flavum (LF), intertransverse ligament, interspinous ligament and supraspinous ligament, were constructed in the preprocessing process of the finite element analysis, and the capsule of the facet joints was reconstructed similarly $[3,27]$.

\section{Spine models after PTED}

The reconstruction PTED model was based on the complete model described above, and the L4-L5 segment was selected for simulation due to the high incidence rate of LDH in this segment [28, 29]. Surgery was simulated on the right side; a $5-\mathrm{mm}$ incision in the annulus was made to simulate the annulus tear and the nucleus was removed to imitate discectomy [7, 8]. Additionally, one-third of the LF on the right side was excised in the two PTED models. All procedures were identical except for whether they were one-quarter or one-half facetectomy procedures of the superior articular process $[5,7]$. Pictorial representation of the simulated PTED procedures are shown in Fig. 2, and magnetic 


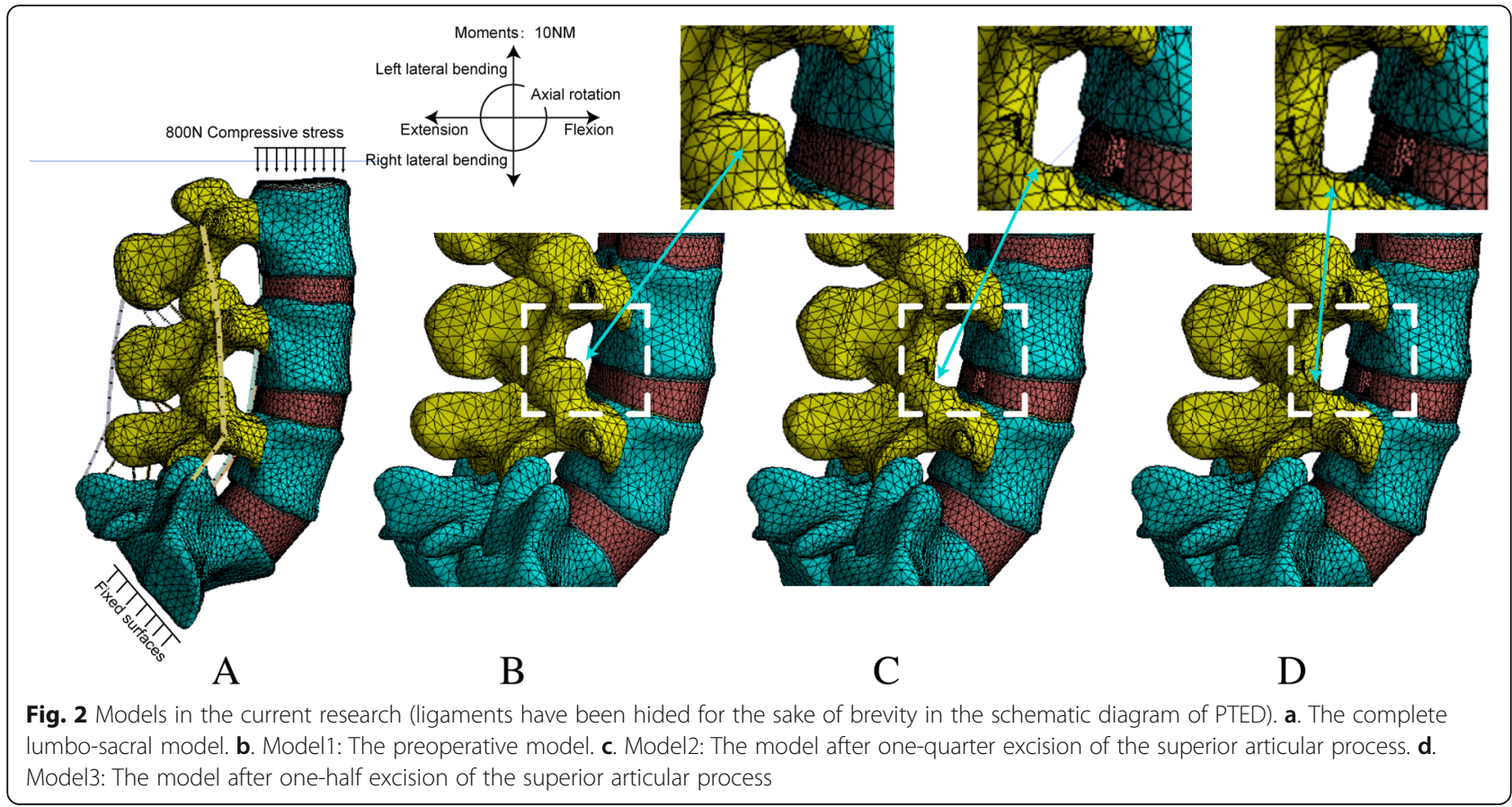

resonance images of patients subjected to PTED in different sides with various grades of facetectomy are shown in Fig. 3.

\section{Boundary and loading conditions}

Boundary and loading conditions were identical in all models. All degrees of freedom were fixed below the inferior surface of S1, and five different loading conditions including flexion, extension, left lateral bending, right lateral bending and axial rotation were simulated by applying $10 \mathrm{NM}$ moments on the superior surface of the L3. All simulation conditions were based on $800 \mathrm{~N}$ of vertical compression [25]. In addition, $85 \%$ of the force was applied on the anterior and the middle columns, while $15 \%$ was applied on the posterior column [30, 31]. For brevity, the complete model was labelled model 1, that after one-quarter excision of the superior articular process as model 2 and that after one-half excision of the superior articular process as model 3 .

The tetrahedral solid elements was selected for this models as it is appropriate for filling models with complex surfaces, and we used mesh refinement in areas where mesh distortion was needed to improve mesh quality and reduce calculation error. The bounded contact type was selected for all surfaces in the lumbosacral model, as the surfaces do not separate under normal stress conditions, except at the facet cartilage surfaces, which were therefore defined as frictionless [25, 27]. Additionally, the centrum, endplates and facet cartilages were defined as being composed of isotropic and homogeneous elastic materials, the nucleus was defined as an 'incompressible fluid bag', the annulus as a hyper-elastic 'Mooney-Rivlin' material and the ligaments as tension-only cable elements. Material properties in the current model were based on published FEM studies (Tables 1 and 2) [32, 33].

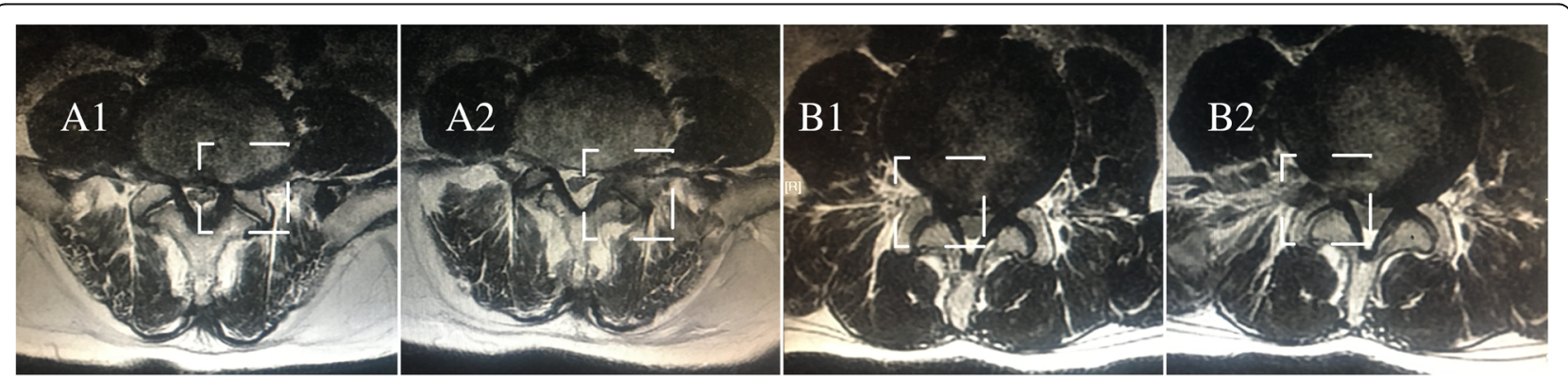

Fig. 3 The magnetic resonance imaging (MRI) of patients subjected to PTED with different grades of facetectomy. $\mathbf{a}$. PTED in the left side. $\mathbf{b}$. PTED in the right side. 1. Preoperative data. 2 .Postoperative data 
Table 1 The material properties used in finite element models

\begin{tabular}{llll}
\hline Components & Young's modulus (Mpa) & Poisson's ratio & Cross-section area(mm $^{22}$ \\
\hline Cortical & 12,000 & 0.3 & $/$ \\
Cancellous & 100 & 0.2 & $/$ \\
Posterior elements & 3500 & 0.25 & $/$ \\
Endplate & 1000 & 0.4 & $/$ \\
Cartilage & 10 & 0.4 & 67.5 \\
Capsular & 26 & 0.3 & 60 \\
ALL & 20 & 0.3 & 21 \\
PLL & 70 & 0.3 & 60 \\
LF & 50 & 0.3 & 10 \\
ITL & 50 & 0.3 & 40 \\
ISL & 28 & 0.3 & 30 \\
SSL & 28 & 0.3 & \\
\hline
\end{tabular}

Note: ALL: anterior longitudinal ligament; PLL:posterior longitudinal ligament; LF:ligamantum flavum; ISL:interspinous ligament; SSL: supraspinal ligament; ITL:intertransverse ligament

\section{Results}

\section{Validation of model reconstruction}

We validated our complete model (model 1) by comparing disc compression values and intradiscal pressure in model 1 with those from two well-validated and repeatedly cited in vitro biomechanical researches, henceforth referred to as 'specimen'. Values of disc compression under a load of $1200 \mathrm{~N}$ in the specimen were $1.6 \pm 0.55,1.6 \pm 0.5$ and $1.3 \pm 0.5 \mathrm{~mm}$ in L3-L4, L4-L5 and L5-S1 IVD segments [34], and values of intradiscal pressure were $0.3 \pm 0.09,0.9 \pm$ 0.26 and $1.85 \pm 0.46 \mathrm{MPa}$ under $300 \mathrm{~N}, 1000 \mathrm{~N}$ and $2000 \mathrm{~N}$ loads, respectively [35]. The disc compression values of our current model were 1.7, 1.5 and 1.1 $\mathrm{mm}$, and the intradiscal pressures were $0.2,0.78$ and $1.49 \mathrm{MPa}$, respectively. Significantly, values from model 1 were within one standard deviation of those reported for the specimen (Fig. 4), except for the intradiscal pressure under $300 \mathrm{~N}$. Considering that it was only $0.01 \mathrm{MPa}$ below the standard deviation and equal to the lowest value in the original data [35], the complete model was well-validated and can be regarded as a reliable representation of the normal spine.

\section{Biomechanical change with different extents of facetectomy}

We choose the L5-S1 segment IVD to investigate changes in maximum shear stress on the annulus

Table 2 The material properties of Intervertebral discs

\begin{tabular}{lcccc}
\hline Annulus & & & Nucleus \\
\cline { 1 - 1 } C1 (MPA) & C2 (MPA) & & Young's modulus (Mpa) & Poisson's ratio \\
\hline 0.2 & 0.05 & 1 & 0.499 \\
\hline
\end{tabular}

due to the elevated levels of morbidity associated with LDH of this segment.The maximum annulus shear stress in the L5 IVD increased with larger extents of facetectomy under most conditions, except during right lateral bending. The variation of the total deformation shows the same trend and which was most significant under extension in model 3 , as it increased by 67.3 and $47.5 \%$, compared to models 1 and 2, respectively (Fig. 5).

The variation in maximum principle strain on the capsule and von Mises stress on the facet cartilage in the L3-L4 segment showed a similar trend, as values increased with higher grades of facetectomy under all loading conditions. With respect to the operated segment (L4-L5), an exception was observed during right lateral bending, in which higher grades of facetectomy led to lower maximum principle strain on the capsule and lower von Mises stress on the facet cartilage in the operated side of the facet joint. Interestingly, corresponding values in the opposite side under the same loading conditions were dramatically higher; compared to the values in models 1 and 2 , the maximum principal strain in model 3 increased by 77.9 and $51.8 \%$ and von Mises stress in the facet cartilage increased by 217.6 and $204.2 \%$, respectively. The patterns of variation in the L5-S1 segment were consistent with those of the upper two segments, but note that all values are obviously higher in this segment. The patterns of change in the two values under different loading conditions are shown in Figs. 6 and 7.

\section{Discussion}

FBSS is a significant postoperative complication with typical symptoms of persistent LBP and has been 

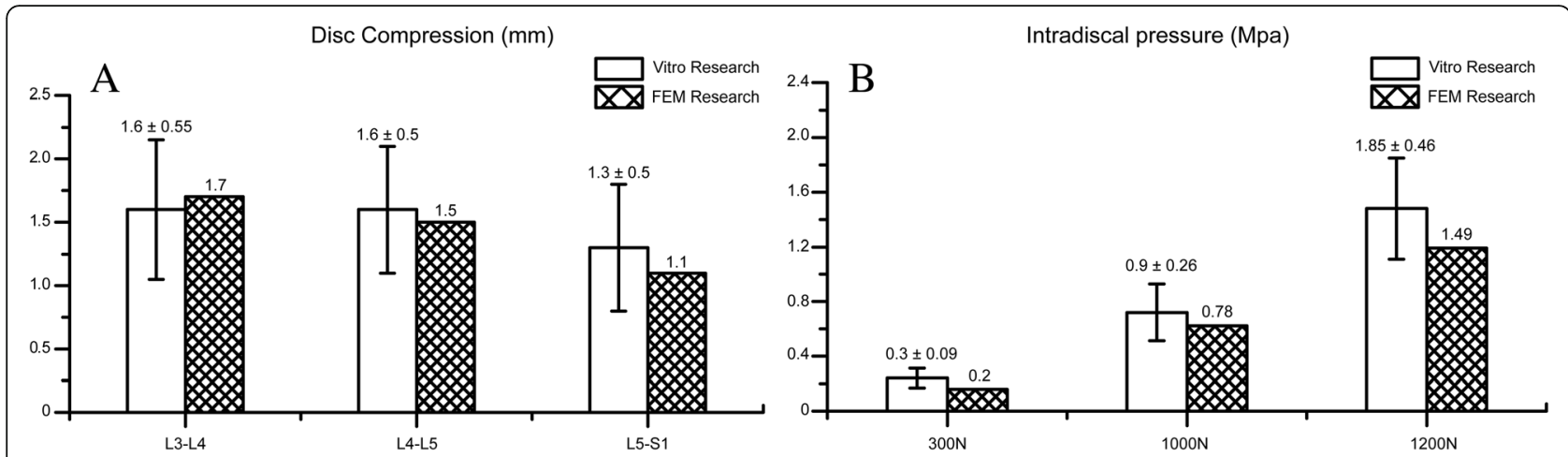

Fig. 4 Validation process for the current model. a. Comparasion of the intradiscal pressure with the validated vitro study. b. Comparasion of the disc compression value with the validated vitro study

reported to be an important predictor of postoperative poor outcome [1, 22, 36]. Considering that biomechanical deterioration is the key trigger of postoperative complications $[2,4-6]$, the investigation of the biomechanical conditions of FBSS is vital to reduce its risk.

Compared to traditional open discectomy, PTED may reduce the risk of FBSS. Previously studies reported that open posterior lumbar surgery will lead to the damage and atrophy of paraspinal muscles, which have been indicated as a significant cause of FBSS [36-38]. Meanwhile, the weakness of paraspinal muscle will result in lumbar instability, a significant trigger of FBSS $[1,39]$. As a minimally invasive surgical method, PTED will not damage the paraspinal muscles and the conclusion that PTED reduces the risk of FBSS seems credible $[39,40]$. However, clinical studies have shown that minimally invasive surgical methods do not significantly decrease morbidity associated with postoperative complications compared to open surgery, and the damage to osteoligamentous structures during the microdiscectomy procedure can also result in biomechanical deterioration $[5,37,41]$. Thus, the conclusion that minimally invasive spine surgery could decrease the risk of FBSS may be unreliable. Given these contradictory conclusions, it is critical to pay attention on the relationship between PTED and FBSS from a biomechanical point of view.

Facetectomy is needed in PTED for accessing the intraspinal region. For patients who suffer from hypertrophy of the facet joints, larger extents of facetectomy are important for exiting nerve root decompression. However, such procedure may be closely associated with postoperative complications $[6,9,11,42]$.

To identify the effect of various extents of facetectomy on morbidity during FBSS, an issue that has not been clearly studied, a three-dimensional lumbosacral model was reconstructed and validated to assess changes in biomechanical indexes that are directly associated with FBSS, namely, maximum shear stress on the annulus in the L5 segment, von Mises stress at the facet cartilage, maximum principle capsular strain on the capsule and the total deformation of current models.

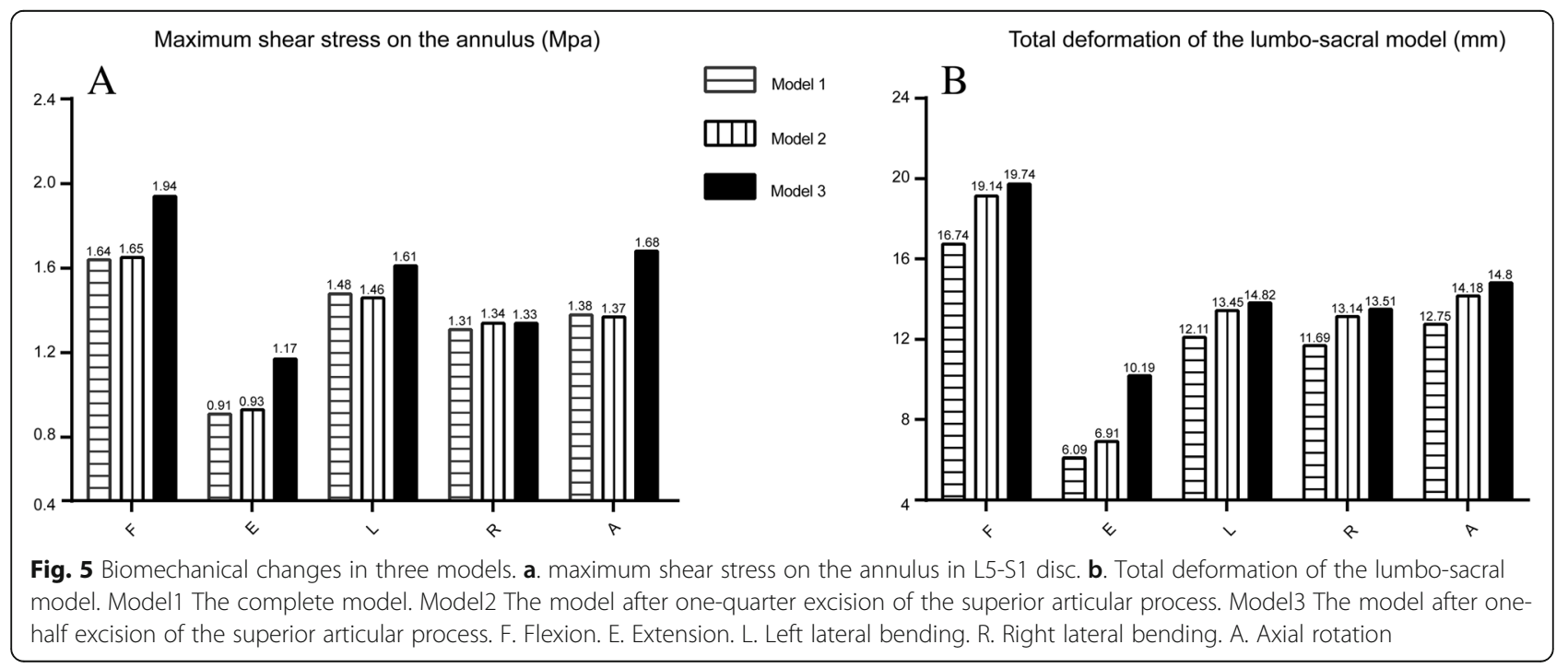


The von Mises stress on the facet cartilage (Mpa)
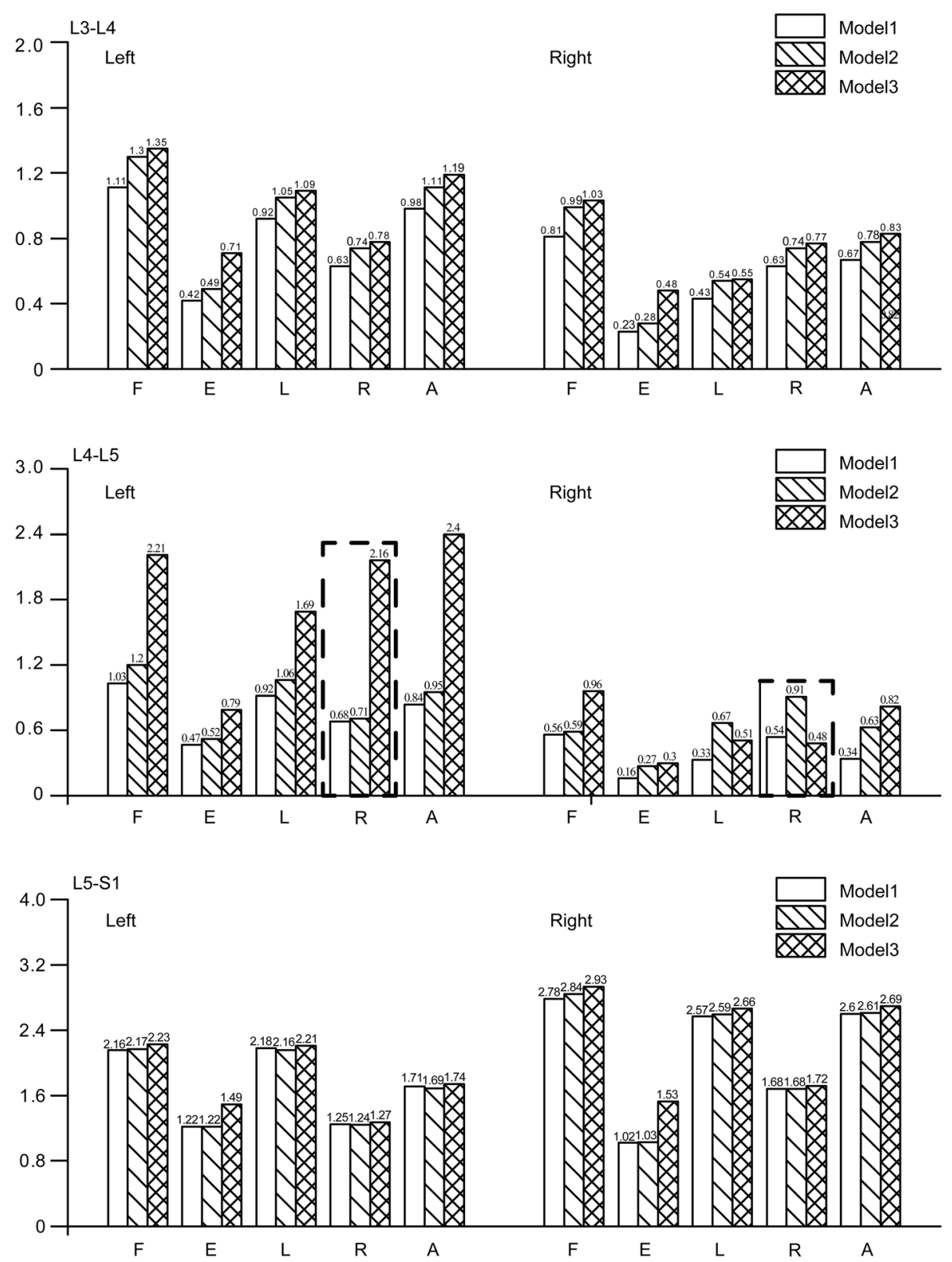

Fig. 6 von Mises stress on the facet cartilage. Model1 The complete model. Model2 The model after one-quarter excision of the superior articular process. Model3 The model after one-half excision of the superior articular process. F. Flexion. E. Extension. L. Left lateral bending. R. Right lateral bending. A. Axial rotation

Causes of LBP that involve facet joints have been recognised as risk factors for more than half century $[19,43]$, and changes in the force applied on the facet surface and to capsular strain are closely associated with facet joint diseases $[18,23,44]$. In the current study, we have discovered that von Mises stress on the facet cartilage increases with larger extents of facetectomy, which may accentuate degeneration of the facet joints $[45,46]$, while an increase in the maximum principal strain on the capsule can result in local neuropathic pain $[16,17]$. Thus, our results indicate that larger extents of facetectomy may lead to facet joint diseases and LBP, especially in the contralateral side and when the body bends in the direction of the operated side.

Notably, we show that the stress on the facet cartilage and the strain on the capsule were the highest in the L5-S1 segment, and such phenomenon may occur when 


\section{Maximum principle strain on the capsule $\left(1 \times 10^{\wedge}-3\right)$}
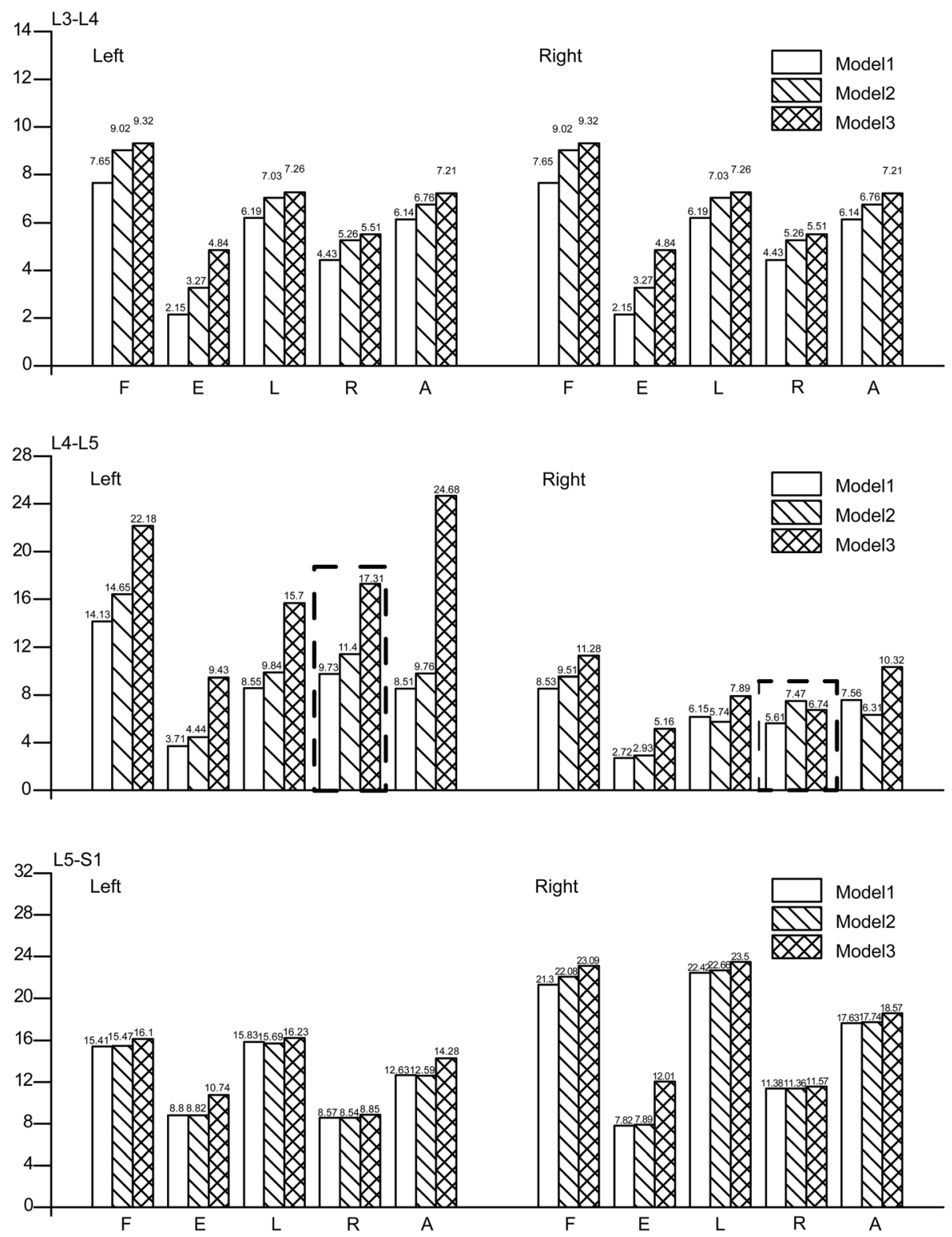

Fig. 7 Maximum principle strain on the capsule. Model 1 The complete model. Model2 The model after one-quarter excision of the superior articular process. Model3 The model after one-half excision of the superior articular process. L left side. R right side. F. Flexion. E. Extension. L. Left lateral bending. R. Right lateral bending. A. Axial rotation

biomechanical indexes is applied close to a fixed surface and specific data for this segment may be less reliable. Nonetheless, as this is a qualitative rather than a quantitative study, we believe that the results are credible.

An increase in the maximum shear stress on the annulus is an important factor that results in radical annulus tears, which may lead to discogenic LBP and LDH, two key triggers of FBSS $[1,12,25,26,36]$. In this study, the maximum shear stress on the annulus obviously increased during flexion and axial rotation with larger extents of facetectomy, and stress concentration can be observed at the posterior annulus (Fig. 8). In addition, the variation trends of biomechanical indexes in the annulus and the facets are same. Considering that facet cartilages and capsules will protect the posterior annulus during torsion and flexion, respectively [15], the risk of annulus tears may be increased with larger extents of facetectomy. 


\section{The maximum shear stress on the annulus (Mpa)}

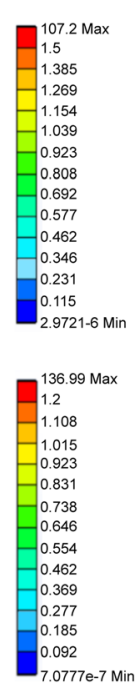

A
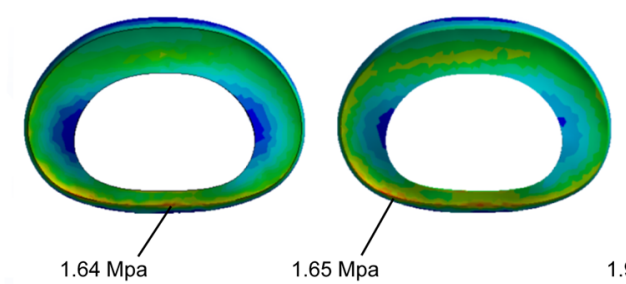

B

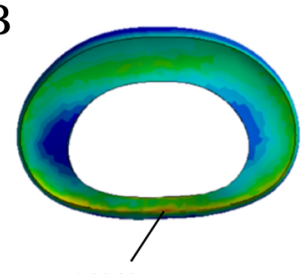

$1.38 \mathrm{Mpa}$
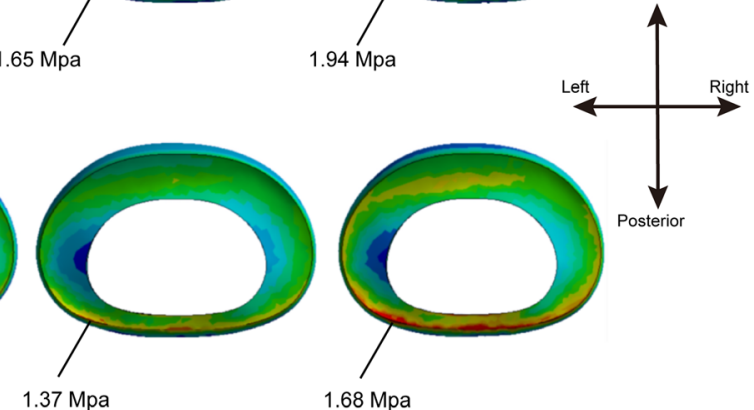

Model1

Model2

Model3

Fig. 8 The nephogram of shear stress on the annulus in L5 disc. a. In flexion. b. In axial rotation. Model1 The complete model. Model2 The model after one-quarter excision of the superior articular process. Model3 The model after one-half excision of the superior articular process

Facet joints are crucial for spine stabilisation, and spine instability is a common cause of FBSS [21, 22, 47, 48]. Postoperative hypermobility will accelerate disc degeneration and result in FBSS $[49,50]$. The increase in the total deformation of the current models is a good indicator of lumbar instability, and we observed this phenomenon with larger extents of facetectomy under all loading conditions.

Finally, note that some patients suffer from severe postoperative LBP even if typical changes in imaging are absent [1, 51]. In such patients, we hypothesise that postoperative deterioration of biomechanical indexes leads to LBP before an organic change could be detected by imaging. Importantly, this phenomenon is further supported by the necessity to avoid, or at least reduce, biomechanical deterioration by surgical intervention. In summary, the results from this study suggest that less facetectomy is better in PTED on the premise of achieving the goal surgery, i.e. to reduce morbidity due to FBSS.

The current conclusion must be accepted on the premise of the awareness of the following limitations. LDH patients who underwent PTED present with varying grades of disc degeneration, facet degeneration and osteoporosis. In addition, this study was conducted under a single load condition rather than different load conditions. These factors influence the change in biomechanical conditions of the spine after facetectomy and can thereby affect risk in FBSS [13, 17, 25, 44]. However, these factors were not incorporated into the present study, and we expect to analyse their effects in future studies.

\section{Conclusions}

Less facetectomy is better in PTED for which may reduce the risk of biomechanical deterioration and consequently FBSS.

\section{Abbreviations}

CT: Computed tomography; FBSS: Failed back surgery syndrome; FEM: Finite element methods; IVD: Intervertebral disc; LBP: Low back pain; LDH: Lumbar disc herniation; LF: Ligamentum flavum; PTED: Percutaneous transforaminal endoscopic discectomy

\section{Acknowledgements}

We acknowledge Prof. Tao Wu for the guidance of the model reconstruction, And Dr. Wuguang Lu and Dr. Juan Ye for the guidance of the manuscript preparation.

\section{Authors' contributions}

LX and JCL contributed to the concept and design of the study. JCL, XYZ received the lumbar $C T$ scan and provided the imaging data of this model. $X Y Z$ and WQX contributed to the model reconstruction. $X Y Z$ and $Z P X$ performed the data analysis. JCL and XYZ wrote the manuscript. All authors read and approved the final manuscript.

\section{Funding}

The current research was funded by the Foundation for leading talent in traditional Chinese medicine of Jiangsu province(2018 SLJ0210), Natural Science Foundation of Jiangsu (BK20151604), Project of Jiangsu province health and family planning commission (2016 BJ16026) and Project of Jiangsu province health and family planning commission (H2018025). The funds provided by the above projects are used for the CT scan, the compensation of volunteer, the polishing of English manuscripts in the mother tongue, the conference affairs and travel expenses of studying courses related to three-dimensional spinal modeling and finite element analysis and the publication charges of this manuscript. 


\section{Availability of data and materials}

All the data of the manuscript are presented in the paper.

\section{Ethics approval and consent to participate}

Ethical approval for this research was obtained from the Ethics Committees of Jiangsu Province Hospital on Integration of Chinese and Western Medicine (2019LWKYS-033).The CT data for the reconstruction of FEM model from a male volunteer, who was one of the authors of this manuscript and knows all of our experiment and informed consent was signed before the $C T$ scan of his lumbar spine.

\section{Consent for publication}

Not applicable.

\section{Competing interests}

The authors declare that they have no competing interests.

\section{Received: 3 January 2019 Accepted: 2 August 2019}

Published online: 09 August 2019

\section{References}

1. Clancy C, Quinn A, Wilson F. The aetiologies of failed Back surgery syndrome: a systematic review. J Back Musculoskelet Rehabil. 2017;30(3): 395-402.

2. Adams MA, Freeman BJ, Morrison HP, Nelson IW, Dolan P. Mechanical initiation of intervertebral disc degeneration. Spine (Phila Pa 1976). 2000; 25(13):1625-36.

3. Mas Y, Gracia L, Ibarz E, Gabarre S, Pena D, Herrera A. Finite element simulation and clinical follow-up of lumbar spine biomechanics with dynamic fixations. PLoS One. 2017;12(11):e0188328.

4. Hsieh YY, Chen CH, Tsuang FY, Wu LC, Lin SC, Chiang CJ. Removal of fixation construct could mitigate adjacent segment stress after lumbosacral fusion: A finite element analysis. Clin Biomech (Bristol, Avon). 2017:43:115-20.

5. Tang S, Rebholz BJ. Does lumbar microdiscectomy affect adjacent segmental disc degeneration? A finite element study. J Surg Res. 2013; 182(1):62-7

6. Paul P, Garton HJ, Gala VC, Hoff JT, Mcgillicuddy JE. Adjacent segment disease after lumbar or lumbosacral fusion: review of the literature. \%. Spine. 2004;29(17):1938-44.

7. Hoogland T, Van dBK, Schubert M, BJS M. Endoscopic transforaminal discectomy for recurrent lumbar disc herniation: a prospective, cohort evaluation of 262 consecutive cases. Spine (Phila Pa 1976). 2008;33(9):973.

8. Gu G, Wang C, Gu X, Zhang H, Zhao Y, He S. Percutaneous Transforaminal endoscopic discectomy for adjacent segment disease after lumbar fusion in elderly patients over 65 years old. World Neurosurgery. 2018;112:e830-6.

9. Dreyfuss P, Halbrook B, Pauza K, Joshi A, Mclarty J, NJS B. Efficacy and validity of radiofrequency neurotomy for chronic lumbar zygapophysial joint pain. Spine (Phila Pa 1976). 2000;25(10):1270-7.

10. Schwarzer AC, Aprill CN, Derby R, Fortin J, Kine G, Bogduk N. The falsepositive rate of uncontrolled diagnostic blocks of the lumbar zygapophysial joints. Pain. 1994;58(2):195-200.

11. Mario JC, Anton ED, Melvin H, Ronald AL, Timothy RK, Michael KRJS. Does superior-segment facet violation or laminectomy destabilize the adjacent level in lumbar transpedicular fixation? An in vitro human cadaveric assessment. 2008:33(26):2868-73.

12. Adams MA, Roughley PJ. What is intervertebral disc degeneration, and what causes it? Spine (Phila Pa 1976). 2006:31(18):2151-61.

13. Qasim M, Natarajan RN, An HS, Andersson GBJ. Damage accumulation location under cyclic loading in the lumbar disc shifts from inner annulus lamellae to peripheral annulus with increasing disc degeneration. J Biomech. 2014;47(1):24-31.

14. Natarajan RN, Andersson GB, Patwardhan AG, TPJJoBE A. Study on effect of graded facetectomy on change in lumbar motion segment torsional flexibility using three-dimensional continuum contact representation for facet joints. J Biomech Eng. 1999;121(2):215-21.

15. Hasegawa K, Kitahara K, Shimoda H, Hara T. Facet joint opening in lumbar degenerative diseases indicating segmental instability. J Neurosurg Spine. 2010;12(6):687-93.

16. Muto M. Degenerative facet joint disease. Neuroradiology. 2011;53(S1):167-8.
17. lanuzzi A, Little JS, Chiu JB, Baitner A, Kawchuk G, Khalsa PS. Human lumbar facet joint capsule strains: I. during physiological motions. Spine J. 2004;4(2) 141-52.

18. Li W, Wang S, Xia Q, Passias P, Kozanek M, Wood K, Li G. Lumbar facet joint motion in patients with degenerative disc disease at affected and adjacent levels. Spine. 2011;36(10):E629-37.

19. Schmidt H, Galbusera F, Rohlmann A, Zander T, Wilke H-J. Effect of multilevel lumbar disc arthroplasty on spine kinematics and facet joint loads in flexion and extension: a finite element analysis. Eur Spine J. 2010;21(S5):663-74.

20. Rohlmann A, Zander T, Bock B, Bergmann G: Effect of position and height of a mobile core type artificial disc on the biomechanical behaviour of the lumbar spine. Proc Inst Mech Eng H J Eng Med 2008, 222(2):229-239.

21. Waguespack A, Schofferman J, Slosar P, Reynolds J. Etiology of long-term failures of lumbar spine surgery. Pain Med. 2002;3(1):18-22.

22. Skaf G, Bouclaous C, Alaraj A, Chamoun R. Clinical outcome of surgical treatment of failed back surgery syndrome. Surg Neurol. 2005;64(6):483-8.

23. Cavanaugh JM, Ozaktay AC, Yamashita HT, AlJJoB K. Lumbar facet pain: biomechanics, neuroanatomy and neurophysiology. J Biomech. 1996;29(9):1117-29.

24. Yang P, Zhang Y, Ding HW, Liu J, Ye LQ, Xiao J, Tu Q, Yang T, Wang F, Sun GG. Pedicle screw fixation with kyphoplasty decreases the fracture risk of the treated and adjacent non-treated vertebral bodies: a finite element analysis. J Huazhong Univ Sci Technolog Med Sci. 2016;36(6):887-94.

25. Ruberté LM, Natarajan RN, Andersson GBJ. Influence of single-level lumbar degenerative disc disease on the behavior of the adjacent segments-a finite element model study. J Biomech. 2009;42(3):341-8.

26. Sengupta DKJS: Clinical Biomechanics of the Spine. 2017, 42 Suppl 7:S3.

27. Masni A, Tanaka M. Biomechanical investigation on the influence of the regional material degeneration of an intervertebral disc in a lower lumbar spinal unit: a finite element study. Comput Biol Med. 2018;98:26-38.

28. Weber H. Lumbar disc herniation. Spine. 1983;8(2):131-40.

29. Kang Q, Li X, Cheng Z, Liu CA. Effects of release and decompression techniques on nerve roots through percutaneous transforaminal endoscopic discectomy on patients with central lumbar disc herniation. Experimental and Therapeutic Medicine. 2017;13(6):2927-33.

30. Rohlmann A, Zander T, Rao M, Bergmann G. Realistic loading conditions for upper body bending. J Biomech. 2009:42(7):884-90.

31. Goel VK, Kong W, Han JS, Weinstein JN, Gilbertson LG. A combined finite element and optimization investigation of lumbar spine mechanics with and without muscles. Spine (Phila Pa 1976). 1993;18(11):1531-41.

32. Rajasekaran S, Babu JN, Arun R, Armstrong BR, Shetty AP, Murugan S. ISSLS prize winner: a study of diffusion in human lumbar discs: a serial magnetic resonance imaging study documenting the influence of the endplate on diffusion in normal and degenerate discs. Spine (Phila Pa 1976). 2004;29(23):2654-67.

33. Chuang W-H, Kuo Y-J, Lin S-C, Wang C-W, Chen S-H, Chen Y-J, Hwang J-R. Comparison among load-, ROM-, and displacement-controlled methods used in the lumbosacral nonlinear finite-element analysis. Spine. 2013;38(5): E276-85.

34. Renner SM, Natarajan RN, Patwardhan AG, Havey RM, Voronov LI, Guo BY, Andersson GBJ, An HS. Novel model to analyze the effect of a large compressive follower pre-load on range of motions in a lumbar spine. J Biomech. 2007:40(6):1326-32.

35. Brinckmann P, Grootenboer $H$, Spine J. Change of disc height, radial disc bulge, and intradiscal pressure from discectomy. An in vitro investigation on human lumbar discs. 1991;16(6):641.

36. Follett KA, BAJNQ D. Etiology and Evaluation of the Failed Back Surgery Syndrome. Neurosurg Q. 1993;3(1).

37. Yee TJ, Terman SW, La Marca F, Park P. Comparison of adjacent segment disease after minimally invasive or open transforaminal lumbar interbody fusion. J Clin Neurosci. 2014;21(10):1796-801.

38. Kim D, Lee S, Sang KC, HJS L. Comparison of Multifidus Muscle Atrophy and Trunk Extension Muscle Strength: Percutaneous versus Open Pedicle Screw Fixation. Spine (Phila Pa 1976). 2005;30(1):123.

39. Zhu R, Niu WX, Zeng ZL, Tong JH, Zhen ZW, Zhou S, Yu Y, LMJCB C. The effects of muscle weakness on degenerative spondylolisthesis: A finite element study. Clin Biomech (Bristol, Avon). 2017;41(1):34-8.

40. Slipman CW, Shin CH, Patel RK, Isaac Z, Huston CW, Lipetz JS, Lenrow DA, Braverman DL, Jr VEJPM. Etiologies of failed back surgery syndrome. Pain Medicine. 2010;3(3):200-14.

41. Radcliff KE, Kepler CK, Jakoi A, Sidhu GS, Rihn J, Vaccaro AR, Albert TJ, ASJSJ $\mathrm{H}$. Adjacent segment disease in the lumbar spine following different treatment interventions. Spine J. 2013;13(10):1339-49. 
42. Schwarzer AC, Aprill CN, Derby R, Fortin J, Kine G, NJP B. The false-positive rate of uncontrolled diagnostic blocks of the lumbar zygapophysial joints. Pain. 1994;58(2):195-200.

43. Badgley CE: The articular facets in relation to low back pain and sciatic radiation, vol. 23; 1941.

44. Park WM, Kim K, Kim YH. Effects of degenerated intervertebral discs on intersegmental rotations, intradiscal pressures, and facet joint forces of the whole lumbar spine. Comput Biol Med. 2013;43(9):1234-40.

45. Fujiwara A, Tamai K, Yamato M, An HS, Yoshida H, Saotome K, AJESJ K. The relationship between facet joint osteoarthritis and disc degeneration of the lumbar spine: an MRI study. J Spinal Disord. 1999:8(5):396-401.

46. Jr OT, Bradford DSJBJR: The inter-relationship of facet joint osteoarthritis and degenerative disc disease. 1991;30(1):16b.

47. North RB, Campbell JN, James CS, Conoverwalker MK, Wang H, Piantadosi S, Rybock JD, Long DMJN. Failed back surgery syndrome: 5-year follow-up in 102 patients undergoing repeated operation. Neurosurgery. 1991;28(28): 685-90 discussion 690-681.

48. Wang H, Ma L, Yang D, Wang T, Liu S, Yang S, WJM D. Incidence and risk factors of adjacent segment disease following posterior decompression and instrumented fusion for degenerative lumbar disorders. Medicine (Baltimore). 2017;96(5):e6032.

49. Bastian L, Lange U, Knop C, Tusch G, Blauth M. Evaluation of the mobility of adjacent segments after posterior thoracolumbar fixation: a biomechanical study. European spine journal : official publication of the European Spine Society, the European Spinal Deformity Society, and the European Section of the Cervical Spine Research Society. 2001;10(4):295-300.

50. Lee CK, Langrana NAJS. Lumbosacral spinal fusion. A biomechanical study. 1984;9(6):574.

51. Rd WA. Spine GSJ: Synopsis: workshop on idiopathic low-back pain. 1982; 7(2):141.

\section{Publisher's Note}

Springer Nature remains neutral with regard to jurisdictional claims in published maps and institutional affiliations.

Ready to submit your research? Choose BMC and benefit from:

- fast, convenient online submission

- thorough peer review by experienced researchers in your field

- rapid publication on acceptance

- support for research data, including large and complex data types

- gold Open Access which fosters wider collaboration and increased citations

- maximum visibility for your research: over $100 \mathrm{M}$ website views per year

At $\mathrm{BMC}$, research is always in progress.

Learn more biomedcentral.com/submissions 